\title{
Methodological approaches to assessment of the efficiency of business entities activity
}

\author{
Olena Pakhnenko, Olga Liuta, Nataliya Pihul \\ Finance, Banking and Insurance Department, Sumy State University, Ukraine \\ corresponding e-mail: o(dot)pakhnenko[at]uabs(dot)sumdu\{dot\}edu\{dot\}ua \\ address:flat 153, building 12, Illins'ka Street, Sumy, Ukraine, 40009
}

\begin{abstract}
The management of stable development of business entities requires the improvement of methodological approaches regarding their efficiency assessment. We think that the efficiency assessment should conduct a comparative analysis with other economic entities regarding the effectiveness of using existing amount of material, financial and labour resources. For a comparative assessment of the operational efficiency of Ukrainian enterprises the authors suggest the method of frontier stochastic analysis. The essence of this approach is to build a standard enterprise with the highest efficiency indicators and calculation of the efficiency coefficients. According to the results of statistical hypotheses testing it is determined that the translog function with the truncated distribution of a random component best describes the investigated functional dependences. According to the results of modelling the efficiency coefficients for every enterprise and period of investigation were received and on the basis of them the ranking of enterprises efficiency was made.
\end{abstract}

JEL Classifications: G30, G32, C14

Keywords: Efficiency, profitability, enterprise, stochastic analysis, frontier analysis

Citation: Pakhnenko, O., Liuta, O., \& Pihul. N. (2018). Methodological approaches to assessment of the efficiency of business entities activity. Business and Economic Horizons, 14(1), 143-151.

http://dx.doi.org/10.15208/beh.2018.12

\section{Introduction}

In modern economic conditions active actions concerning the improvement of the domestic enterprises efficiency become of particular relevance. The management of stable development of business entities requires the improvement of methodological approaches regarding their efficiency assessment. The problem of assessing the economic efficiency of an enterprise's activity is primarily due to the definition of appropriate efficiency criteria and model parameters. The classic approach to efficiency analysis through profitability indicators does not always produce objective results and requires consideration of a variety of economic and production factors. In practice it is important to evaluate efficiency of business entities through methodology which includes two aspects. The first aspect allows us to calculate certain relative efficiency indicators that characterize a particular enterprise. The second aspect is based on the conduction of a comparative analysis with other economic entities regarding the effectiveness of using existing amount of material, financial and labour resources.

The purpose of this study is to evaluate the effectiveness of business entities with the use of stochastic frontier analysis tools based on data about financial and economic activities of Ukrainian enterprises. The study employed the following methods: logical generalization - during investigation of indicators characterizing the efficiency of business entities activity, frontier stochastic analysis - during creation of a standard enterprise with the highest efficiency indicators and calculation of the efficiency coefficients, the method of ranking - for a qualitative interpretation of the results of the investigation by assigning 
the rank to enterprises according to the level of efficiency of their activity, comparative analysis - during comparing calculated indicators of the level of efficiency and profitability of enterprises with the use of tools of frontier stochastic analysis.

The information base of the study consists of 40 enterprises of Ukraine (10 enterprises of 4 types of economic activity - machine building, light industry, food industry and building materials industry). Study period - 5 years. Economic-mathematical modeling is based on the cross-branch study of enterprises, which can reduce the adequacy of calculating the coefficients of the model's efficiency, because the features of the structure of expenses by types of economic activity are not taken into account.

\section{Literature review}

Problems in evaluating the effectiveness of business entities are the subject of scientific researches both domestic and foreign scientists. Significant contribution to the study of this issue was carried out by leading Ukrainian scientists.

Grechko \& Grechuxin (2016) noted that the evaluation of efficiency is an effective tool for informational and analytical maintenance of the enterprise's activity. The evaluation results are the basis for making managerial decisions.

The evaluation of the enterprise's performance includes the use of various indicators, which are calculated on the basis of the financial performance of the company: the profit; profitability of sales; profitability of assets; profitability of equity and borrowed capital; profitability of the equity. Cherep \& Sinyekayeva (2014) believe that the main factor in improving the performance of enterprises is the introduction of innovations. So the evaluating method of the results of innovations in enterprises can be carried out by using groups of such indicators: indicators of production efficiency, indicators of financial efficiency, and indicators of investment efficiency. Matyux (2014) determined that enterprises should have well-formulated strategic goals and objectives with a given scale of their achievement. Competitive leadership, the dynamics of industry growth, the concentration of consumers, the possibility of access to loan capital are evaluated using this approach. Khokhlov \& Balykov (2012) noted that the assessment of the efficiency of the enterprise should be carried out using an optimization factor model of efficiency.

Fic \& Malinowski (2016) said that communication infrastructure has great influence on the functioning of enterprises. The author proposed to use a synthetic measure of economic effectiveness of enterprises, seizing on an earlier selected set of diagnostic variables. The application of synthetic measures, that use one aggregate indicator instead of a series of variables to describe objects, enables us to quantify the multidimensional nature of economic operations and systematize them in a linear way.

The creation of a system of indicators for assessing should also take into account the ownership as well as the size of the enterprise. Jenkins (1984) determined that a public enterprise is expected to fulfil many objectives: generate a financial surplus; help reducing unemployment; develop skills; and contribute to growth, technical progress, and the correction of regional imbalances. The evaluation of public enterprise performance should be done in view of the multiplicity of objectives thrust upon it. Kotane \& KuzminaMerlino (2012) paid their attention on the evaluation of small-companies performance and determined that the evaluation of small-companies performance should take into account that small enterprises have limited financial resources and difficulties in receiving them. 
Nickell, Nicolitsas, \& Dryden (1997) believe that an important role in determining the effectiveness of the enterprise has three external factors in generating improved productivity performance in companies: product market competition, financial market pressure and shareholder control. Sun (2011) determined that evaluation of enterprises should be done with the using of econometric theory and modern analysis techniques to in-depth analysis of enterprise management process. It summarizes the assessment of business situation and expects future development of enterprises.

At the same time, despite the considerable number of publications devoted to this problem and thorough investigations carried out in this area it should be noted that the question of the methodology for evaluating the effectiveness of business entities needs further development using modern mathematical apparatus.

\section{Research model}

Today the successful development of enterprises is determined by solving the tasks of the reliable assessment of the efficiency of business entities activity and improving its effectiveness. In our opinion, it is expedient for enterprises to analyse not only their own performance, but also to compare it with similar indicators of enterprises in the corresponding industry or main competitors. It will allow us to increase the level of reliability of the evaluation results. Such approach will enable business entities to identify and adapt existing examples of the effective functioning of other companies in order to improve their own performance indicators. For a comparative assessment of the operational efficiency of Ukrainian enterprises we use the method of frontier stochastic analysis. The essence of this approach is to build a standard enterprise with the highest efficiency indicators and calculation of the efficiency coefficients. We will calculate these coefficients in the following way: the ratio of the profit function values of the studied enterprises to the corresponding indicator of the standard enterprise (potentially possible maximum value of the parameter). It should be noted that the formation of the standard enterprise and the potential level of the efficiency is based on empirical data on the investigated enterprises by selecting the best indicators. In other words, for the disinfecting factors (enterprise costs) such level is determined when the minimum value corresponds to the maximum value of the target function. For factors-stimulators (revenues) - we, on the contrary, select the maximum values that provide the maximum profit.

Implementation of the stochastic analysis method of the enterprises efficiency activity includes several stages, namely:

1. Formalization of the model, determination of the target function and deterministic influence factors;

2. Formation of input data of Ukrainian enterprises and their normalization;

3. Model specification through choosing the functional form of the model and the type of the random component distribution using the statistical criterion of maximum reasonableness;

4. Calculation of model parameters and efficiency factors based on the use of software Frontier 4.1;

5. Qualitative interpretation of the results of stochastic analysis of the enterprises activity efficiency. 
Two basic approaches can be used to conduct a stochastic efficiency analysis: efficiency analysis based on the evaluation of a production function or on the basis of profit function (Battese \& Coelli, 1995). In this study we used the second approach and chose the operating profit of the company as the target function of the model. It allowed us to illustrate directly the correlation between the volume of expenses incurred by the enterprise and the financial result received from production and sales of products without taking into account the influence of investment and financial activity.

The stochastic function of the enterprise profit can be represented as follows:

$$
\ln Y_{i t}=\beta \ln X_{i t}+\left(V_{i t}-U_{i t}\right), \quad i=1, \ldots, N, t=1, \ldots, T
$$

Where, $Y_{i t}$ - the output parameter of the model - the financial result of the operating activity of the $i$-th enterprise in the period $t ; \beta$ - vector of unknown parameters; $X_{i t}$ vector of deterministic variables model for $i$-th enterprise in the period $t ; V_{i t}$ - statistical error; $U_{i t}$ - a component of efficiency that reflects the influence of the vector of controlled variables of the latent nature.

Depending on the set of the vector of the model deterministic variables two variations of the stochastic profit function - standard and alternative can be used. For the standard profit function it is assumed that the markets are perfectly competitive and prices are fixed. Therefore, the vector of deterministic impact factors is formed by the prices of resources (input parameters of the model), enterprises influence on the size of the output parameter - operating profit - only through a change in the volume of the resources usage and volumes of production. Alternative profit function assumes that the volumes of output parameters (volume of sales) and the price of input parameters (the price of resources) are specified. Profit maximization is due to a change in the price of output parameters and the number of input parameters.

Two variants of the vector of input deterministic model parameters are formed to conduct a stochastic analysis of the Ukrainian enterprises efficiency. The first option for a model construction involves conducting analysis on the basis of the quantitative indicators of the resources usage and the second option is based on the resources prices.

Thus, the component composition of the vector input parameters for the first model includes indicators of the usage volumes of the various resources types in the enterprise:

$\mathrm{C}_{1}$ - volume of current assets, thousand UAH;

$\mathrm{C}_{2}$ - volume of non-current assets, thousand $\mathrm{UAH}$;

$\mathrm{C}_{3}$ - the number of employees in the enterprise, persons.

The component composition of the vector input parameters for an alternative model includes the cost expression of the resources used in the production process:

$\mathrm{C}_{1}{ }^{*}$ - material expenses, thousand UAH;

$\mathrm{C}_{2} *$ - depreciation, thousand $\mathrm{UAH}$;

$\mathrm{C}_{3}{ }^{*}$ - payroll fund and social contributions, thousand UAH. 
For both functions we chose financial result from operational activity $O P_{i t}$ as an output parameter (target function). In contrast to the net financial result this indicator characterizes the success and efficiency of the main activity of the enterprise without considering the components of financial and investment income and expenses.

\section{Empirical results}

\subsection{Data and model specification}

The information base of the study comprised 40 Ukrainian enterprises $(10$ enterprises of 4 types of economic activity - engineering, light industry, food industry and construction materials industry) (Stock market infrastructure development agency of Ukraine (SMIDA, 2017). On the basis of the financial statements in the investigated enterprises for the period of 5 years an array of input data for both variants of the economic-mathematical model of stochastic efficiency analysis has been formed and their normalization has been carried out. Methodology of applied frontier stochastic analysis involves the use of natural logarithms of the input and output model parameters. Normalization of input data is to get rid of negative indicators values through equal increase of all values of the corresponding parameter.

In the next stage the specification of the model is carried out by selecting its functional forms and the distribution type of the random component using the maximum likelihood estimation. Within the framework of each model two representation versions of its functional form were considered - the translogarithmic function and the Kobb-Douglas function. Also it was made 2 variants of the distribution of the random component - the truncated normal and half-normal distributions.

According to the results of statistical hypotheses testing it is determined that the translog function with the truncated distribution of a random component best describes the investigated functional dependences. This conclusion is valid for both variations of the profit function.

Application of the criterion of maximum likelihood includes the calculation of natural logarithms of the values of functions of long and short hypotheses:

$$
L R=2\left(l_{L}-l_{S}\right)=2 \ln \frac{L_{L}}{L_{S}}
$$

Where, $l_{L}, l_{S}$ - the value of the logarithmic function of the likelihood of long and short models, respectively.

The results of statistical testing of hypotheses in the studied models for verifying the fulfilment of the criterion of maximum likelihood is presented in Table 1. 


\section{TABLE 1. RESULTS OF STATISTICAL TESTING OF HYPOTHESES BASED ON THE CRITERION OF MAXIMUM LIKELIHOOD}

\begin{tabular}{|c|c|c|}
\hline & Zero hypothesis $\left(\mathrm{H}_{0}\right)$ & Alternative hypothesis $\left(\mathrm{H}_{1}\right)$ \\
\hline Functional form & \multicolumn{2}{|c|}{ LLF (log likelihood function) for model 1} \\
\hline Type of distribution & Koba-Douglas function & Translog function \\
\hline Half-normal distribution & $-0.28247588 \mathrm{E}+03$ & $-0.16613732 E+03$ \\
\hline Truncated normal distribution & $-0.27862147 E+03$ & $0.34484866 \mathrm{E}+02$ \\
\hline Functional form & \multicolumn{2}{|c|}{ LLF (log likelihood function) for model 2} \\
\hline Type of distribution & Koba-Douglas function & Translog function \\
\hline Half-normal distribution & $-0.28331820 E+03$ & $-0.17420852 E+03$ \\
\hline Truncated normal distribution & $-0.27970636 \mathrm{E}+03$ & $-0.15335599 \mathrm{E}+00$ \\
\hline
\end{tabular}

The translog function provides more flexible approach to the formalization of the correlation between variables. In addition, its use testifies to the existence of more complicated correlation between variables which cannot be expressed only by effects of the first order. Consequently, the formalized form of the profit function in the constructed model has the form (Coelli, 1996):

$$
\begin{aligned}
\ln \left(O P_{i t}\right)= & \beta_{0}+\beta_{1} \ln \left(C_{1 i t}\right)+\beta_{2} \ln \left(C_{2 i t}\right)+\beta_{3} \ln \left(C_{3 i t}\right)+\beta_{4} \ln \left(C_{1 i t}\right)^{2}+ \\
& \beta_{5} \ln \left(C_{2 i t}\right)^{2}+\beta_{6} \ln \left(C_{3 i t}\right)^{2}+\beta_{7} \ln \left(C_{1 i t}\right) \ln \left(C_{2 i t}\right)+ \\
& \beta_{8} \ln \left(C_{1 i t}\right) \ln \left(C_{3 i t}\right)+\beta_{9} \ln \left(C_{2 i t}\right) \ln \left(C_{3 i t}\right)+\left(V_{i t}-U_{i t}\right)
\end{aligned}
$$

Where, $V_{i t}$ - statistical error; $U_{i t}$ - a component of inefficiency that reflects the vector influence of the controlled latent variables.

\subsection{Results and discussion}

At the next stage of the implementation of the stochastic analysis method of the enterprises efficiency the calculation of model parameters and efficiency coefficients is performed. In order to automate calculations the appropriate software is selected Frontier 4.1. According to the simulation results the efficiency coefficients for each enterprise and the research period are obtained. The coefficients are the basis for building the enterprise performance ratings for each research period (the first position in the rating is assigned to the company with the highest efficiency factor, etc.).

Table 2 presents the results of the investigated enterprises rating by the level of efficiency according to two built models, as well as the corresponding indicators of profitability for the last year of investigation.

"Motor Sich" PJSC (private joint stock company) is the leader by the level of efficiency in both ratings, as well as in terms of product profitability $(106.2 \%)$ in the last year of investigation. The last place in both ratings in this year takes "Podilsky Cement" PJSC which received the largest amount of operating losses. Although, the enterprise is not the worst in terms of profitability. 


\section{TABLE 2. RATINGS AND PROFITABILITY INDICATORS OF UKRAINIAN COMPANIES IN THE LAST YEAR OF INVESTIGATION}

\begin{tabular}{|c|c|c|c|c|}
\hline Company & $\begin{array}{l}\text { Rating by the level of } \\
\text { efficiency, model } 1\end{array}$ & $\begin{array}{l}\text { Rating by the level of } \\
\text { efficiency, model } 2\end{array}$ & $\begin{array}{c}\text { Product } \\
\text { profitability, } \%\end{array}$ & $\begin{array}{l}\text { Net profit / Net } \\
\text { sales, \% }\end{array}$ \\
\hline $\begin{array}{l}\text { PJSC "Kyiv confectionery factory } \\
\text { "ROSHEN" }\end{array}$ & 18 & 23 & 3.7 & 4.4 \\
\hline PJSC "Lviv confectionery factory "Svitoch" & 22 & 34 & 22.1 & 11.7 \\
\hline PrJSC "Enzym Company" & 5 & 22 & 35.4 & 16.1 \\
\hline PJSC "Kombinat "Pridniprovs'kiy" & 17 & 33 & 4.2 & 2.1 \\
\hline $\begin{array}{l}\text { PJSC "Dniprovskiy krokhmalepatokoviy } \\
\text { kombinat" }\end{array}$ & 21 & 24 & 12.1 & 5.8 \\
\hline PJSC "Kremenchukm'yaso" & 32 & 27 & 3.1 & -3.0 \\
\hline $\begin{array}{l}\text { PrJSC "Mineral water plant Morshinsky } \\
\text { "OSCAR" }\end{array}$ & 6 & 25 & 16.1 & 11.5 \\
\hline $\begin{array}{l}\text { PrJSC "Dnepropetrovsk Food } \\
\text { Concentrates Plant" }\end{array}$ & 11 & 19 & 16.9 & 11.7 \\
\hline PJSC "Poltavakonditer" & 26 & 31 & 9.5 & 7.9 \\
\hline PJSC "Production Association KONTI" & 34 & 26 & 10.0 & 4.3 \\
\hline PJSC "Ukraina" & 12 & 14 & 8.8 & -8.6 \\
\hline PJSC "Cherkasy silk integrated plant" & 13 & 18 & 15.8 & 11.0 \\
\hline PJSC "Knitted wear factory "ROZA" & 2 & 5 & 5.9 & 0.6 \\
\hline PJSC "Sophia" & 25 & 10 & 2.0 & 2.3 \\
\hline PJSC "Ternopil association "Texterno" & 30 & 17 & -6.4 & -47.7 \\
\hline PJSC "Sewing enterprise "Yunist" & 28 & 16 & 36.4 & -991.3 \\
\hline PrJSC "KSK "Chekseal" & 23 & 11 & 16.7 & -224.4 \\
\hline PJSC "Boguslav Cloth Factory" & 33 & 6 & 5.3 & 5.1 \\
\hline $\begin{array}{l}\text { PrJSC "Factory of technical fabrics } \\
\text { "Tehnofiltr" }\end{array}$ & 14 & 4 & -0.3 & 12.5 \\
\hline PJSC "Kharkov rope factory" & 16 & 7 & -8.1 & -2.4 \\
\hline PJSC "Motor Sich" & 1 & 1 & 106.2 & 24.6 \\
\hline PJSC "Azovmash" & 8 & 28 & -15.6 & -19.3 \\
\hline PJSC "ZTR" & 36 & 36 & 4.8 & -243.6 \\
\hline PJSC "SPC "Girnichi mashini" & 20 & 39 & -100.0 & $\mathrm{x}$ \\
\hline PJSC "Nord" & 31 & 30 & 7.2 & -3.8 \\
\hline PJSC "Turboatom" & 9 & 2 & 94.4 & 60.6 \\
\hline PJSC "Kherson Shipyard" & 38 & 32 & -33.0 & -4120.1 \\
\hline PJSC "AutoKrAZ" & 39 & 35 & 26.0 & -16.2 \\
\hline PJSC "Dniprovagonmash" & 37 & 20 & -59.4 & -122.0 \\
\hline PJSC "PTMZ" & 24 & 21 & 24.7 & 13.9 \\
\hline
\end{tabular}

It is also worth to note that the enterprise PJSC "SPC "Girnichi mashini" did not carry out production activities in the last year of investigation. Its net income, cost and other components of operating expenses were equal 0 . However, according to the current rating the company occupies the 20th and 39th positions in the 1st and 2nd models. The relatively high position in the 1 st model (mid-rating) is due to the fact that the company has available current and non-current assets on the balance. The lack of economic activity in this period did not ensure profit generation; however, no significant losses were received in comparison with other investigated enterprises.

\section{Conclusion}

Summarizing the results of the conducted stochastic frontier analysis of the efficiency in Ukrainian enterprises for the period of 5 years we can draw the following conclusions: 
a. The two options of the determination of the vector composition of the deterministic parameters used during their modelling demonstrated different evaluation results of the efficiency of the investigated enterprises. This allows us to draw conclusion about the dependence of the analysis of the enterprises efficiency on the selected parameters of its evaluation, significant and insignificant influence parameters;

b. In the second model, in which the deterministic influence factors are the costs of the enterprise (material costs, depreciation, payroll fund), the dependence of the rating of the enterprises efficiency on its branch affiliation is observed. This is a confirmation of the fact that the differences in the structure of enterprise costs, as well as in the levels of labour and material consumption of production in various industries are essential factors for assessing the efficiency of enterprises;

c. There is no statistically significant correlation between the established by the results of the stochastic analysis of the efficiency ratings and the indicators of the enterprises profitability (Figure 1).

\section{FIGURE 1. CORRELATION BETWEEN EFFICIENCY RATINGS AND INDICATORS OF THE ENTERPRISES PROFITABILITY}

a. rating of enterprises according to the model 1 - profitability of the product

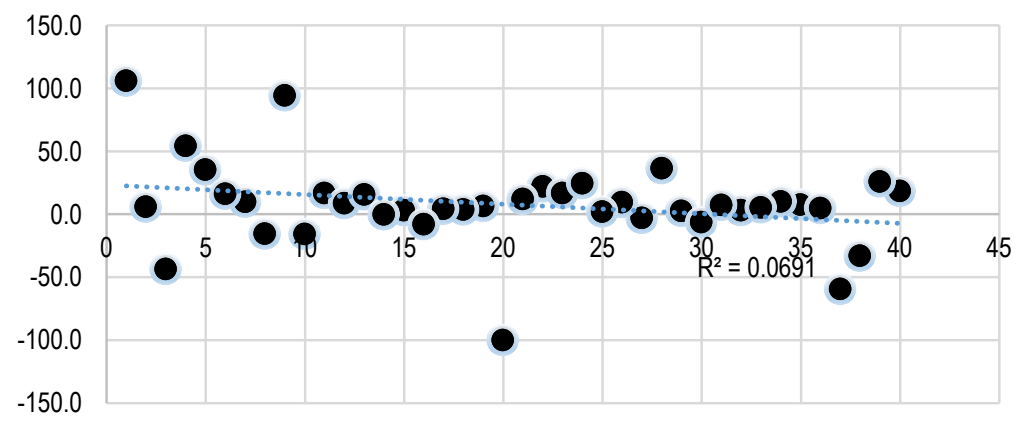

b. rating of enterprises according to the model 2 - profitability of the product

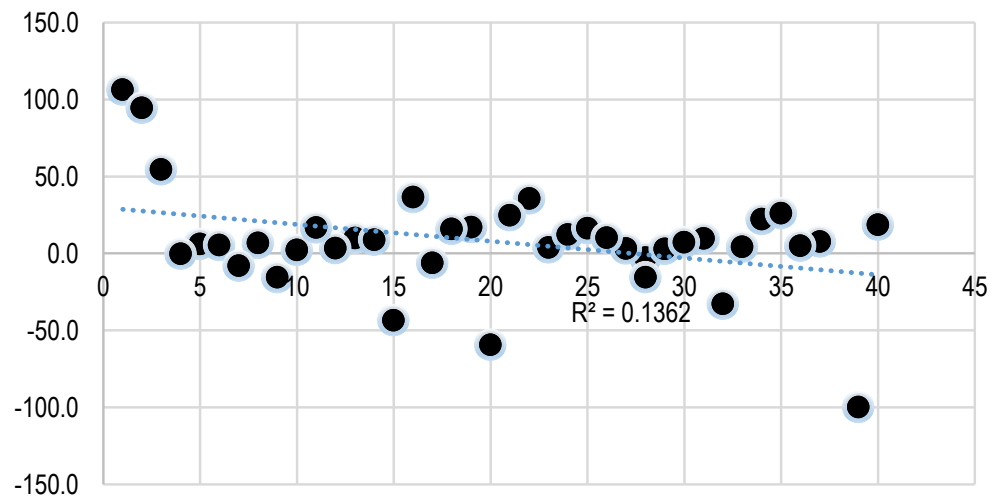

Source: Own elaboration. 
Consequently, profitability indicators cannot be used as the unique or main criterion for the enterprise activity efficiency, although, they are important indicators of the enterprise financial condition assessment.

\section{References}

Battese, G., \& Coelli, T. (1995). Model for technical inefficiency effects in a stochastic frontier production function for panel data. Emperical Economics, 20, 325-332.

Cherep, A. V., \& Sinyekayeva, O. D. (2014). Methodical principles of an estimation of efficienacctivity of the enterprises of mechanical engineering. Business Inform, 4, 124-129.

Coelli, T. (1996). A guide to frontier version 4.1: A computer program for stochastic frontier production and cost function estimation. CEPA Working Papers, 7, 33.

SMIDA (2017). Stock market infrastructure development agency of Ukraine (SMIDA). Database system of Stock market infrastructure development agency of Ukraine. Retrieved March 3, 2017 from http://www.smida.gov.ua/about

Fic, M., \& Malinowski, M. (2016). Communication infrastructure and enterprise effectiveness. Retrieved March 3, 2017 from Springer International Publishing Switzerland: link.springer.com/chapter/10.1007/978-3-319-21139-8_4

Grechko, A. V., \& Grechuxin, A. S. (2016). Estimation of efficiency of production activity of the enterprise. Retrieved March 3, 2017 from http://www.economy.nayka.com.ua/pdf/1_2016/44.pdf

Hohlov, M. P., \& Baly 'kov, S. V. (2012). Determination of indicators for assessing the effectiveness of the enterprise. Bulletin of the National Technical University. Retrieved March 3, 2017 from http://repository.kpi.kharkov.ua/handle/KhPI-Press/6073

Jenkins, G. P. (1984). Evaluation of performance of industrial public enterprises: criteria and policies. Development Discussion Papers, 7 , 13-23.

Kotane, I., \& Kuzmina-Merlino, I. (2012). Assessment of financial indicators for evaluation of business performance. European Integration Studies. Retrieved March 3, 2017 from http://www.eis.ktu.lt/index.php/EIS/article/view/1554

Matyux, S. A. (2014). Research of modern methods of assessing the effectiveness of organizations. Economic analysis, 3, 79-85.

Nickell, S., Nicolitsas, D., \& Dryden, N. (1997). What makes firms perform well. European Economic Review, 1, 783-796.

Sun, W. (2011). Study on performance evaluation of enterprise. Key Engineering Materials, 467-469, 1122-1125. Retrieved March 3, 2017 from http://subject.org.cn/ 